TAMADDUN : Jurnal Pendidikan dan Pemikiran Keagamaan

P-ISSN : 1693-3941; E-ISSN : 2722-2632

Vol. 22 No.1 Bulan Januari Tahun 2021

\title{
MATERI AKHLAK DALAM KETELADANAN KHADIJAH MENURUT IBRAHIM MUHAMMAD HASAN AL-JAMAL
}

\author{
Adinda Nur Afifa Kusaini' ${ }^{1}$, Muyasaroh ${ }^{2}$, Ode Moh. Man Arfa Ladamay ${ }^{3}$, Hasan Basri ${ }^{4}$ \\ ${ }^{1}$ Universitas Muhammadiyah Gresik, \\ email: adindanurafifakusaini@gmail.com \\ ${ }^{2}$ Universitas Muhammadiyah Gresik, \\ email:muyas@umg.ac.id \\ ${ }^{3}$ Universitas Muhammadiyah Gresik, \\ email:arf@gmail.com \\ ${ }^{4}$ Universitas Muhammadiyah Gresik, \\ email: hasanbasri@gmail.com
}

\begin{abstract}
Abstrak: Seiring dengan perkembangan zaman wanita mengalami krisis akhlak, mereka seperti kehilangan sosok teladan. Cara untuk memperbaiki akhlak muslimah saat ini adalah salah satunya mengkaji sejarah dan biografi kehidupan Khadijah binti Khuwailid dalam buku Khadijah teladan agung wanita mukminah karya Ibrahim Muhammad Hasan Al-Jamal. Penelitian ini merupakan jenis penelitian literatur yang dilaksanakan menggunakan metode riset perpustakaan (liberary research). Jenis penelitian ini menggunakan penelitian kualitatif. Sumber data yang digunakan dalam penelitian ini yaitu buku Khadijah karya Ibrahim Muhammad Hasan Al-Jamal (primer) dan buku-buku yang relevan dengan penelitian ini. Metode analisisnya menggunakan analisis deskriptif dan analisis isi. Berdasarkan penelitian pustaka yang telah dilakukan teladan akhlak bagi muslimah yang terkandung dalam buku Khadijah teladan agung wanita mukminah dapat disimpulkan terdiri dari akhlak terhadap Allah (meliputi: mentauhidkan Allah, takwa kepada Allah, dzikrullah, tawakal, dan syukur), akhlak terhadap diri sendiri (meliputi: sabar, amanah, iffah / memelihara kesucian diri, sidqu / benar, wafa' / menepati janji, teguh), akhlak terhadap sesama (meliputi: berbuat baik kepada sesama, suka menolong orang lain / dermawan), akhlak terhadap orang tua (meliputi: memuliakan orang tua), akhlak terhadap suami (meliputi: perhatian dan pengertian terhadap suami, selalu mendukung suami dalam hal kebaikan, setia kepada suami, meringankan beban suami, menaati perintah suami).
\end{abstract}

Kata Kunci : Teladan, Akhlak, Muslimah, Khadijah 


\section{PENDAHULUAN}

$\mathrm{A}$

1-Qur'an adalah kitab suci umat Islam, bekal setiap muslim, dan petunjuk bagi kehidupan umat manusia. Al-Qur'an menyebutkan bahwa segala sesuatu itu pasti ada pasanganya, baik pada manusia, hewan, tumbuh-tumbuhan, dan lain sebagainya (Adam Cholil, 2014: 13). Allah menciptakan perempuan dengan sangat istimewa. Buktinya ada satu surat dalam Al-Qur'an yang dikhususkan membahas tentang perempuan yaitu surat AnNisa' yang terdiri dari 176 ayat dan tergolong sebagai surat Madaniyyah (surat yang diturunkan di Madinah). Wanita salihah adalah penentram batin, penguat semangat berjuang dan beribadah seorang suami. Wanita salilah juga dapat menyejukkan qolbu (hati), saat berbicara tutur katanya menenangkan batin, dan senyum di wajahnya dapat menghilangkan lelah suaminya. Prinsipnya wanita salihah ialah wanita yang taat pada Allah dan taat pada Rasul (Muhammad Bambang, 2011). Wanita salihah akan selalu istiqamah dalam menuntut ilmu, baik dari alam maupun lingkungannya serta mengamalkannya. Ciri wanita salihah adalah wanita yang taat dan mau berbakti pada suaminya.

Sejarah dipenuhi dengan potret kepahlawanan. Kisah mereka diceritakan dari generasi ke generasi, menjadi teladan mulia, dan sebagai contoh yang di ikuti. Perjalanan panjang sejarah Islam tidak lepas dari kontribusi kaum wanita atau muslimah. Di antara muslimah yang patut dijadikan teladan ideal adalah Khadijah binti Khuwailid, seorang istri sekaligus wanita pertama yang beriman dan meneguhkan kerasulan Nabi Muhammad saw (Ibrahim Muhammad Hasan Al-Jamal, 2014: 6). Melihat kontribusi Sayyidah Khadijah pada Islam, baik sebagai perempuan maupun istri salihah yang patut dijadikan teladan bagi wanita pada masa sekarang, karena beliau merupakan wanita yang pertama-tama beriman dan meneguhkan kerasulan Muhammad saw serta membantu dakwah nabi dengan mengorbankan harta dan jiwanya hanya untuk dipergunakan dalam menyebarkan Agama Islam. Kepatuhan dan kesetiaan Sayyidah Khadijah dalam membantu dakwah Nabi Muhammad saw, sampai beliau pernah berpesan jika beliau meninggal sedangkan perjuangan dakwah Islam belum selesai, sekiranya tidak ada kayu untuk menyeberangi sungai ataupun lautan untuk berdakwah maka galilah kuburku dan jadikan tulangku untuk rakit.

Posisi akhlak dalam Islam adalah sangat penting. Akhlak sebagai nilai moralitas dalam Islam yang memberikan peran penting bagi kehidupan, baik yang bersifat individual maupun kolektif (Samsul Munir Amin, 2016: 51). Rasulullah adalah suri teladan yang baik dalam berbagai aspek kehidupan dan contoh pribadi yang memiliki akhlak mulia, sedangkan wanita muslimah yang patut dijadikan teladan adalah istri pertama Rasulullah yaitu Sayyidah Khadijah binti Khuwailid karena beliau adalah wanita pertama yang beriman kepada Allah dan meneguhkan kerasulan Muhammad saw serta membantu berjuang dakwah untuk menyebarkan Agama Islam. Seiring dengan perkembangan zaman wanita mengalami krisis akhlak. Mereka seperti kehilangan sosok teladan, karena semakin jauh meninggalkan teladan sejati yang telah terbukti kemuliaan akhlaknya. Banyak wanita yang tidak mengetahui kemuliaan sebagai 
TAMADDUN : Jurnal Pendidikan dan Pemikiran Keagamaan

P-ISSN : 1693-3941; E-ISSN : 2722-2632

Vol. 22 No.1 Bulan Januari Tahun 2021

perempuan, sehingga ketika Allah menjadikan ia mulia, ia melepaskan jubah kemuliaannya. Pada era milenium ini semakin banyak wanita tak bermoral, seperti memakan obat-obatan terlarang, melakukan seks bebas di luar perkawinan, memakai pakaian ketat, dan banyak wanita yang menghilangkan kodratnya sebagai wanita.

Islam telah mengangkat tinggi derajat wanita setelah datangnya Islam. Kenyataannya pada saat ini banyak wanita yang kembali ke derajat seperti zaman jahiliah. Mereka seolah lupa apa yang sudah disabdakan oleh Rasulullah bahwa sebaik-baik perhiasan dunia adalah wanita salihah. Berdasarkan latar belakang masalah tersebut, peneliti tertarik melakukan penelitian yang berjudul "Materi Akhlak dalam keteladanan Khadijah menurut Ibrahim Muhammad Hasan Al-Jamal" yang mana hasil penelitian ini diharapkan digunakan sebagai referensi tambahan guna mempelajari bagaimana seharusnya menjadi wanita salihah. Tujuan penelitian ini adalah untuk mengetahui teladan akhlak bagi muslimah dalam buku Khadijah karya Ibrahim Muhammad Hasan Al-Jamal.

\section{Teladan}

Arti kata teladan menurut Kamus Besar Bahasa Indonesia adalah sesuatu (perbuatan, barang, dsb) yang patut dicontoh dan ditiru. Kata "Teladan" dalam bahasa arab di ungkapkan dengan kata "uswah" yang artinya ikutan, mengikuti yang di ikuti (Armai Arief, 2002: 117). Berdasarkan penjelasan dari arti kata tersebut dapat disimpulkan bahwa teladan adalah hal-hal yang dapat ditiru atau dicontoh oleh seseorang dari orang lain baik dari ucapan, tindakan, sifat, dan sebagainya. Teladan yang dimaksud di sini adalah teladan yang baik, teladan yang dapat dijadikan patokan dalam bertindak, berbicara, dan berperilaku. Keteladanan merupakan salah satu metode pendidikan dalam Islam yang didasarkan pada Al-Qur'an dan As-Sunnah. Sumber teori keteladanan terdapat pada surat Al-Ahzab ayat 21, Al-Mumtahanah ayat 4 dan 6, hadits Bukhari no 7246.

\section{Akhlak}

Kata akhlak berasal dari bahasa Arab yang merupakan bentuk jamak dari kata khuluq, yang berarti adat kebiasaan, perangai, tabiat, dan muru'ah (Samsul Munir Amin, 2016: 1). Secara bahasa akhlak dapat di artikan sebagai budi pekerti, watak, atau tabiat. Akhlak adalah suatu keadaan yang ada pada jiwa seseorang, yang lahir perbuatan-perbuatan secara spontan, tanpa memerlukan pemikiran dan pertimbangan terlebih dahulu. Di sini terlihat jelas bahwa akhlak merupakan kondisi mental seseorang yang sudah tertanam kuat dan menjadi kebiasaan. Perbuatan yang dilakukan jika baik, maka akhlaknya baik, tetapi jika perbuatan yang dilakukan buruk, maka akhlaknya buruk.

Tiga unsur utama yang terdapat dalam ajaran Agama Islam yaitu akidah, syariah, dan akhlak. Al-Qur'an dan hadis merupakan sumber utama ajaran Islam. Inti dari ajaran Islam 
adalah ketauhidan yang dalam wacana ilmu masuk dalam kategori aqidah (keimanan), akidah yang dianut memanifestasikan dalam dua bentuk yaitu syariah (ibadah dan muamalah) dan akhlak. Aqidah Islam dalam Al-Qur'an disebut iman, bukan hanya berarti percaya, melainkan keyakinan yang mendorong seorang muslim untuk berperilaku. Syariah mengatur hubungan manusia dengan Tuhan disebut ibadah dalam arti khusus (thaharah, shalat, zakat, puasa, haji), sedangkan hubungan manusia dengan manusia atau dengan alam lainya disebut dengan muamalah. Akhlak adalah tingkah laku, tabiat atau perangai, perbuatan yang menjelaskan tentang baik buruk, mengatur pergaulan manusia, dan menentukan tujuan akhir dari usaha dan pekerjaannya (Toto Suryana dkk, 1997: 188).

\section{Wanita Muslimah}

Di dalam Al-Qur'an kita akan menemukan beberapa istilah perempuan yaitu an-nisa', mar'ah, atau imro'ah dan untsa. Wanita merupakan sebutan yang digunakan untuk manusia yang berjenis kelamin perempuan, sedangkan perempuan adalah manusia berjenis kelamin betina (https://id.wikipedia.org/wiki/Wanita). Istilah perempuan merujuk kepada orang yang telah dewasa maupun anak-anak. Wanita merupakan panggilan umum untuk menggambarkan perempuan dewasa. Pria yang memeluk Agama Islam disebut "muslimin" sedangkan wanita disebut "muslimah". Berdasarkan pengertian tersebut dapat penulis simpulkan bahwa wanita muslimah adalah seorang perempuan dewasa yang beragama Islam dengan hanya menyembah kepada Allah swt. Beberapa kriteria yang mencerminkan wanita muslimah: (1) Beriman dan bertakwa kepada Allah swt, (2) Melaksanakan kewajiban sebagai muslim (menjalankan salat wajib, puasa, zakat, dan ibadah lain yang diperintahkan oleh Allah), (3) Menutup aurat, (4) Memiliki akhlak yang baik, (5) Berbakti kepada orang tua dan suami, (6) Memiliki ilmu dan mampu mengurus keluarganya.

Akhlak wanita muslimah meliputi: (1) Akhlak terhadap Allah yakni: Beriman hanya kepada Allah dengan iman yang benar, Menaati perintah Allah, Berserah diri kepada Allah, Bersyukur, Ikhlas dan rida menerima keputusan Allah setelah berusaha dan bertawakal, Berdo'a memohon pertolongan kepada Allah; (2) Akhlak terhadap Rasulullah yakni; Ikhlas menyatakan pengakuan dan bersaksi bahwa Nabi Muhammad adalah Rasul Allah (Haya binti Mubarok Al-Barik, 1999: 120), Cinta kepada Rasul dengan mengucapkan selawat dan salam kepada Nabi Muhammad saw, Taat kepada apa yang di perintahkan Rasul dan menghidupkan sunnahnya, Percaya atas semua berita yang di sampaikan Rasulullah saw, Menghormati para ulama sebagai pewaris Nabi saw dan melaksanakan hukum Allah dan Rasul; (3) Akhlak terhadap diri sendiri yakni: Sabar dalam menghadapi cobaan yang diberikan oleh Allah swt, Amanah dalam melaksanakan suatu hak yang dipercayakan kepada kita, Jujur dalam segala hal, baik dari perkataan maupun perbuatan, Menepati janji yang sudah dibuat atau disepakati, karena menurut ajaran Islam janji adalah hutang yang harus di bayar, Menjaga kesucian diri dengan memelihara hati (qalbu) dari hal-hal yang tercela; (4) Akhlak terhadap suami yakni: Menaati 
TAMADDUN : Jurnal Pendidikan dan Pemikiran Keagamaan

P-ISSN : 1693-3941; E-ISSN : 2722-2632

Vol. 22 No.1 Bulan Januari Tahun 2021

suami, Menjaga kehormatan, harta, kemuliaan, dan perasaan suami, Melaksanakan hak suami, Tidak boleh melawan dan menuduh suami tanpa bukti, Percaya kepada suami dan berterima kasih dengan pemberian suami.

\section{Khadijah}

Sayyidah Khadijah adalah wanita suci yang dilahirkan di Ummul-Qura pada tahun 68 sebelum Hijrah Nabawy, yang kira-kira sama dengan lima belas tahun sebelum Tahun Gajah (Ahmad Khalil Jam'ah, 2007: 2). Ayahnya bernama Khuwailid bin Asad bin Abdul Uzza, sedangkan Abdul Uzza adalah saudara Abdul Manaf, salah seorang kakek Nabi. Keduanya adalah anak Qushay bin Kilab. Di sinilah garis keturunan Sayyidah Khadijah bertemu dengan Nabi Muhammad, pada kakek ke empat yaitu Qushay bin Kilab. Ibunya bernama Fatimah bintu Za'idah bin Al-Asham Qursyiyah, dari Bani Amir bin Lu'ay. Sayyidah Khadijah adalah anak pertama dari delapan bersaudara. Empat saudara wanita bernama: Hala, Asma (Halidah), Hindun, dan Rukayah, serta tiga saudara laki-laki bernama: Naufal, Awam, dan Hizam (Sibel Eraslan, 2012: 6). Sayyidah Khadijah adalah istri pertama Rasulullah dan orang pertama yang beriman dari kalangan wanita. sebelum menikah dengan Nabi Muhammad, Sayyidah Khadijah pernah menikah dua kali. Suami pertamanya bernama Halah bin Zurarah Banasy At-Tamimy yang di karuniai dua orang anak laki-laki yang bernama Hindun dan Halah. Setelah dua tahun suami pertamanya meninggal dunia dan membuatnya menjanda. Kemudian ia dinikahi oleh Atiq bin Abid Al-Makhzumy dan mereka memiliki satu anak perempuan.

Sayyidah Khadijah adalah wanita cerdas dan sukses dalam mengembangkan bisnis sehingga beliau dikenal banyak kalangan. Kelebihan Sayyidah Khadijah dalam menata bisnis di antaranya adalah berperan sebagai direktris profesional (berperan dibalik layar / tidak terjun langsung ke lapangan untuk mengelola bisnisnya), membangun jaringan perdagangan antar negara (bukan hanya Mekkah, dagangannya menjalar hingga ke negeri Syam), menaruh kepercayaan pada mitra bisnis yang profesional dan terjaga kualitas kejujuranya, serta tidak membuat mata rantai yang panjang dalam pasokan barang (pemodal - mitra bisnis - konsumen). Sayyidah Khadijah menikah dengan Rasulullah pada usia 40 tahun dan Rasul sendiri berusia 25 tahun, ada yang mengatakan bahwa usianya belum genap 40 tahun, hanya sedikit lebih tua daripada Rasulullah. Pernikah dengan Rasulullah dikaruniai 6 orang anak. Dua putra Khadijah yaitu al-Qasim dan Abdullah wafat saat balita. Anak-anak perempuan Khadijah tumbuh besar yakni Zainab, Ruqayyah, Ummu Kalstum, dan Fatimah al-Zahrah (Yoli Hemdi, 2008: 6). Semua putri Rasulullah meninggal dunia saat Rasul masih hidup, kecuali Fatimah.

Sayyidah Kahdijah adalah wanita pertama yang menyambut dakwah Rasulullah, wanita yang pertama masuk Islam dan beriman kepada Allah dan Rasul-Nya, mukminah pertama yang begitu besar pengorbanannya terhadap dakwah Islam. Beliau mendukung dakwah Rasul dengan jiwa dan hartanya. Sayyidah Khadijah setia mendampingi Rasulullah dan ikut menanggung 
beban yang amat berat akibat ejekan penghinaan, dan penolakan yang kejam dari orang-orang kafir Quraisy pada masa itu. Kurang lebih 25 tahun Sayyidah Khadijah menemai Rasulullah dalam suka maupun duka. Kepergian Sayyidah Khadijah menyisakan pengalaman hidup yang indah di hati Rasulullah dan dan kaum muslimin. Tidak seorang pun di kota Mekkah yang berkata bahwa sayyidah Khadijah pernah menyakiti seseorang. Jibril memberi kabar gembira dua kali kepada Khadijah melalui Nabi Muhammad ketika masih hidup di dunia, yang pertama: ia mendapat salam dari Rabb semesta alam yang disampaikan dari tujuh lapis langit dan malaikat jibril sendiri, kedua: ia mendapat rumah di surga yang terbuat dari bambu dan mutiara tanpa terdengar bising maupun menimbulkan kelelahan (Mahmud Al-Mishri, 2006: 14)

\section{Ibrahim Muhammad Hasan Al-Jamal}

Ibrahim Muhammad Hasan Al-Jamal, seorang penulis muslim spesialis buku-buku penuntun Islam dan sejarah asal Madinah. Beliau mempunyai beberapa karya tulis antara lain adalah sebagai berikut: Ibrahim Muhammad Hasan Al-Jamal, seorang penulis muslim spesialis buku-buku penuntun Islam dan sejarah asal Madinah. Beliau mempunyai beberapa karya tulis antara lain adalah sebagai berikut: (a) Khadijah perempuan teladan sepanjang masa, (b) Amīr al-Muslimīn Yūsuf ibn Tāshfīn : Qāhir al-Ṣalībīyīn fī al-Gharb wa-muwaḥhịid al-Maghrib waal-Andalus, 400-500 H, (c) Zawjāt al-nabī Muḥammad : wa-asrār al-ḥikmah fī ta'addudihin, (d) Risālah ilá ḥukkām al-Muslimīn, (e) Ta'addud al-zawjāt fī al-Islām : al-radd 'alá iftirā’āt almughrị̣̄̄n fī Miṣr, (f) Fiqh al-mar'ah al-Muslimah : `ibadat, mu`amalat

Buku Khadijah Teladan Agung Wanita Mukminah karya Ibrahim Muhammad Hasan AlJamal banyak mengulas mengenai biografi atau sejarah hidup Sayyidah Khadijah, sosok wanita yang sangat inspiratif dalam berjuang di jalan Allah. Beliau adalah sosok teladan ideal bagi muslimah yang nyata kontribusinya bagi Islam dan nyata pula kemuliaan akhlaknya. Menurut Ibrahim Muhammad Hasan Al-Jamal Sayyidah Khadijah adalah figur paling tunduk kepada perintah Allah, paling memahami kebenaran dan syariat Allah, penolong agama Allah, selalu menjaga hak-hak suami, berbakti kepada keluarga dan anak-anak, simpatik kepada yang miskin, dan penolong orang-orang yang terzalimi. perjalanan hidup mendampingi dakwah Islam bersama dengan Rasulullah. Beliau orang yang pertama kali beriman kepada Allah dan Rasul-Nya dan sangat setia kepada Rasulullah saw yang rela memberikan seluruh hartanya untuk berdakwah di jalan Allah. Buku ini menjelaskan masa paling berpengaruh dalam sejarah Islam, masa di mana dakwah bermula, masa di mana Nabi Muhammad menghadapi pertentangan dan hadangan dari orang-orang yang merasa terganggu dan terancam dengan dakwah. 
TAMADDUN : Jurnal Pendidikan dan Pemikiran Keagamaan

P-ISSN : 1693-3941; E-ISSN : 2722-2632

Vol. 22 No.1 Bulan Januari Tahun 2021

\section{METODE}

Pendekatan dalam penelitian ini menggunakan penelitian studi pustaka atau library research, yaitu research yang dilakukan di beberapa tempat kepustakaan atau arsip-arsip hasil penyimpanan penelitian. Data yang di pakai bersumber dari buku-buku, majalah-majalah, artikel-artikel, ensiklopedia Islam, dan tulisan-tulisan (Mardalis, 2009: 28). Objek dalam penelitian yang ingin peneliti teliti ialah akhlak Khadijah dalam buku Khadijah karya Ibrahim Muhammad Hasan Al-Jamal. Jenis Penelitian ini merupakan penelitian kualitatif. Menurut Denzin \& Lincoln (1994) mengemukakan bahwa penelitian kualitatif adalah penelitian yang menggunakan latar alamiah dengan menafsirkan fenomena yang terjadi dan dilakukan dengan melibatkan berbagai metode yang ada.

Sumber data primer penelitian ini ialah buku Khadijah Teladan Agung Wanita Mukminah karya Ibrahim Muhammad Hasan Al-Jamal. Sumber data sekunder adalah sumber-sumber lain yang sangat relevan dengan pembahasan, baik itu berupa buku, artikel, makalah, jurnal, website ataupun yang lainnya yang berkaitan dengan penelitian ini. penelitian ini menggunakan teknik pengumpulan data berupa dokumentasi yaitu teknik mencari data mengenai hal-hal atau variabel seperti buku, catatan, transkrip, surat kabar, majalah, foto, notulen, rapat, agenda, dan sebagainya (Suharsimi Arikunto, 2006: 231). Penelitian ini bersifat literatur, maka metode analisis data yang digunakan peneliti ialah analisis deskriptif yaitu usaha untuk mengumpulkan dan menyusun suatu data, kemudian dilakukan analisis terhadap data-data tersebut dalam bentuk uraian naratif dan analisis isi yaitu teknik penelitian yang ditujukan untuk membuat kesimpulan dengan mengidentifikasi isi pesan pada suatu buku. Data yang sudah dikumpulkan kemudian dikelompokkan dan di analisis isinya secara kritis selanjutnya di simpulkan sebagai jawaban dari rumusan masalah yang ada.

\section{HASIL DAN PEMBAHASAN}

Pembahasan ini akan penulis jelaskan tentang teladan akhlak bagi wanita muslimah dalam buku Kahdijah karya Ibrahim Muhammad Hasan Al-Jamal. Sayyidah Khadijah merupakan figur seorang muslimah yang akhlaknya dapat kita jadikan teladan. Akhlak baik (akhlak mahmuda) yang dimiliki Sayyidah Khadijah meliputi akhlak terhadap Allah, akhlak terhadap diri sendiri, akhlak terhadap sesama, akhlak terhadap orang tua, dan akhlak terhadap suami.

\section{a. Akhlak terhadap Allah:}

1. Mentauhidkan Allah yaitu meyakini bahwa Allah adalah Tuhan semesta alam, Allah adalah satu-satunya Tuhan yang wajib kita sembah, dan Allah juga yang mengatur kehidupan semua makhluk hidup. Mentauhidkan Allah merupakan salah merupakan salah satu kewajiban kita sebagai umat muslim. Kita sebagai muslimah harus percaya bahwa Dzat yang maha segalanya hanya Allah swt. 
2. Takwa kepada Allah yaitu meyakini bahwa Allah itu ada, Taqwa kepada Allah dengan menjalankan segala perintah-Nya dan menjauhi segala apa yang dilarang oleh Allah. Orang yang bertakwa adalah orang yang merasa bahwa setiap gerak dan kegiatannya ia merasa bahwa Allah tahu segala sesuatu yang dia lakukan sehingga ibadahnya hanya untuk Allah dan hanya mengharap ridanya dan takut jika melakukan sebuah kesalahan karena setiap perbuatan akan di catat oleh malaikat Allah.

3. Dzikrullah yaitu mengingat dan menyebut nama Allah di mana pun, kapan pun, dan dalam keadaan apa pun agar menghasilkan ketenangan dan kedamaian hati. Allah sayang dan cinta kepada hamba yang mengingat dan menyebut nama-Nya, kita sebagai seorang muslim tidak boleh hanya mengingat Allah dalam keadaan susah saja tetapi tetap mengingat Allah pada saat senang. Keutamaan berzikir dapat membersihkan hati, firasat menjadi tajam, cepat terkabulnya doa, menghasilkan ketenangan, kedamaian, dan kebahagiaan.

4. Tawakkal yaitu berserah diri kepada Allah / menyerahkan segala sesuatu kepada Allah setelah berusaha dengan semaksimal mungkin. Tawakal merupakan gambaran keteguhan hati dalam menggantungkan diri kepada Allah, menjalani usaha dilakukan oleh tubuh sedangkan tawakal dilakukan oleh hati.

5. Syukur yaitu menerima pemberian Allah dengan ikhlas dan memanfaatkan nikmat yang diberikan Allah dengan sebaik-baiknya. Allah telah memberikan nikmat baik berupa pendengaran, penglihatan, kesehatan, keamanan, dan nikmat lainya yang tak terhitung jumlahnya. Kita juga harus bersyukur dengan nikmat Iman dan Islam yang Allah berikan.

\section{b. Akhlak terhadap diri sendiri:}

1. Sabar yaitu menerima segala ujian dari Allah dengan ikhlas karena apa pun yang ditetapkan Allah pasti yang terbaik untuk hamba-Nya. Sabar dibagi menjadi tiga yaitu: sabar dalam ketaatan, sabar dalam meninggalkan maksiat, sabar ketika ditimpa musibah.

2. Amanah yaitu sifat dapat dipercaya dan bisa menjaga segala bentuk yang dititipkan. Amanah merupakan melaksanakan suatu hak yang dipercayakan kepadanya, baik hak kepada Allah maupun hak kepada hamba.

3. Iffah (menjaga kesucian diri) yaitu menjaga diri dari hal-hal yang dapat mendatangkan fitnah dan yang dapat menghancurkan kehormatan kita sebagai muslimah. Menurut Al-Ghazali kesucian diri terbagi menjadi 4 bagian yaitu: kesucian panca indra, kesucian jasad, kesucian dari memakan harta orang lain, dan kesucian lisan. 
TAMADDUN : Jurnal Pendidikan dan Pemikiran Keagamaan

P-ISSN : 1693-3941; E-ISSN : 2722-2632

Vol. 22 No.1 Bulan Januari Tahun 2021

4. Sidqu (benar) adalah dengan memberitahukan fakta sesuai dengan kebenarannya, tidak menambah-nambahi atau mengurangi baik dalam perkataan maupun perbuatan dan berani membenarkan apa yang sesuai dengan syariat Islam. Seseorang yang benar-benar mukmin selalu berkata benar dan berpegang teguh pada ucapannya, dan Allah akan meneguhkan pendiriannya.

5. Wafa' (menepati janji) yaitu menepati kesepakatan sesuai dengan apa yang sudah kita ucapkan karena janji adalah hutang yang harus di bayar. Menepati janji dapat menambah kepercayaan seseorang kepada diri kita, mempunyai banyak teman, dan di hargai oleh orang lain.

6. Teguh yaitu meyakini pendiriannya yang dianggapnya benar dan tidak goyah dengan apa yang sudah diyakininya. Teguh dalam Islam disebut dengan istiqamah. Ada tiga tahap dalam istiqamah yaitu: istiqamah dengan hati, istiqamah dengan lisan, dan istiqamah dengan perbuatan.

\section{c. Akhlak terhadap sesama:}

1. berbuat baik kepada sesama yaitu dengan membantu orang lain dengan apa yang kita punya dan apa yang kita bisa. Membantu orang yang sedang kesusahan adalah kewajiban kita kepada sesama manusia, karena kita juga makhluk sosial yang membutuhkan bantuan orang lain. Ajaran Islam memerintahkan untuk berbuat baik kepada sanak saudara / sesama, setelah menunaikan kewajiban kepada Allah dan orang tua.

2. Suka menolong orang lain (dermawan) yaitu menolong orang lain dengan memberikan sebagian harta kepada orang yang membutuhkan, tanpa mengharap imbalan. Apabila ada yang memerlukan bantuan yang bersifat materi, kita bantu dengan materi. Sedangkan ada yang mengalami kegelisahan kita mencoba menghibur dan menasihati. Karena bantuan tidak hanya bersifat materi, tetapi juga moril dan terkadang bantuan moril lebih besar artinya dibanding dengan bantuan materi.

\section{d. Akhlak terhadap orang tua:}

1. memuliakan orang tua yaitu dengan menghormati, membahagiakan, dan mendoakan orang tua karena orang tua adalah penyebab turunnya ampunan dan rahmat Allah. Memuliakan orang tua merupakan faktor utama diterimanya doa seseorang, karena doa orang tua cepat terkabul terutama doa dari seorang ibu. 


\section{e. Akhlak terhadap suami:}

1. Perhatian dan pengertian kepada suami yaitu mencurahkan perhatian dengan memenuhi dan melayani kebutuhan suami serta mengerti apa pun keadaan suami. Sebagai istri sudah menjadi tanggung jawab untuk melayani suami, dari yang berkaitan dengan pakaian, makanan, hingga dalam urusan ranjang. Istri harus melayani suami dengan penuh kebaikan. Hal ini bertujuan agar ada hubungan timbal balik yang seimbang antara suami dan istri.

2. Selalu mendukung suami dalam hal kebaikan yaitu dengan mendukung memotivasi suami kegiatan suami selama apa yang dilakukan itu baik dan tidak menyalahi syariat Islam. Mendukung suami bisa dengan cara memotivasi agar memiliki semangat dalam melakukan kebaikan. Memotivasi adalah bentuk kasih sayang seorang istri untuk suami, dengan itu istri sudah berusaha untuk mempertahankan rumah tangganya.

3. Setia kepada suami yaitu menerima apa pun keadaan suami baik suka maupun duka dan selalu berada di samping suami serta tidak menghianati suami. Setia kepada suami merupakan kewajiban sebagai seorang istri. Setia bisa dilakukan dengan cara menerima kekurangan dan kelebihan suami, percaya terhadap suami, dan pandai menjaga diri.

4. Meringankan beban suami yaitu membantu suami, baik dalam hal pekerjaan ataupun yang lain sesuai dengan kemampuan istri agar pekerjaan suami menjadi lebih ringan. Sebagai seorang istri meringankan beban suami merupakan kewajiban, baik itu dalam urusan pekerjaan ataupun yang lainya, sesuai dengan kemampuan yang dimiliki istri. Istri yang senantiasa berusaha membantu suami akan mendapatkan keberkahan dari suaminya. Begitu pun sebaliknya jika suami membantu istrinya, dengan begitu akan tercipta keluarga yang harmonis, bahagia, dan penuh dengan kedamaian.

5. Menaati perintah suami yaitu jika suami menyuruh, istri harus segera melaksanakannya selama perintah dari suami itu baik dan tidak bermaksiat ataupun menyekutukan Allah. Salah satu wanita yang dicintai Allah adalah wanita yang selalu menaati perintah suaminya. Menaati suami merupakan bagian dari kemuliaan seorang istri. istri yang taat kepada suaminya hingga akhir hayat, dan suaminya rida serta merasa senang, maka Allah akan memasukkannya ke dalam surga

\section{SIMPULAN}

Berdasarkan pembahasan dan analisis mulai dari bab I sampai bab IV, peneliti akan mengambil kesimpulan untuk menjawab pokok permasalahan yang ada dalam penelitian. Yakni mengenai teladan akhlak bagi muslimah dalam buku Khadijah teladan agung wanita 
TAMADDUN : Jurnal Pendidikan dan Pemikiran Keagamaan

P-ISSN : 1693-3941; E-ISSN : 2722-2632

Vol. 22 No.1 Bulan Januari Tahun 2021

mukminah. Buku Khadijah ini mengandung teladan akhlak terhadap Allah (meliputi: menauhidkan Allah, takwa kepada Allah, dzikrullah, tawakal, syukur), akhlak terhadap diri sendiri (meliputi: sabar, amanah, Iffah / memelihara kesucian diri, sidqu / benar, wafa' / menepati janji, teguh), akhlak terhadap sesama (meliputi: berbuat baik kepada sesama, suka menolong orang lain / dermawan), akhlak terhadap orang tua (meliputi: memuliakan orang tua), dan akhlak terhadap suami (meliputi: perhatian dan pengertian terhadap suami, selalu mendukung suami dalam hal kebaikan, setia kepada suami, meringankan beban suami, menaati perintah suami)

\section{REFERENSI}

Al-Barik, Haya binti Mubarok. (1999). Ensiklopedi Wanita Muslimah. Jakarta: Darul Falah.

Al-Jamal, Ibrahim Muhammad Hasan. (2014). Khadijah Teladan Agung Wanita Mukminah. Surakarta: Al-Andalus.

Al-Mishri, Mahmud. (2006). 35 Shahabiyah (jilid 1). Jakarta: Al-I’tishom Cahaya Umat.

Amin, Samsul Munir. (2016). Ilmu Akhlak. Jakarta: Amzah.

Arief, Armai. (2002). Pengantar Ilmu Metodologi Pengantar Islam. Jakarta: Ciputat Pers.

Arikunto, Suharsimi. (2006). Prosedur Penelitian Suatu Pendekatan Praktik. Jakarta: PT. Rineka Cipta.

Bambang, Muhammad. (2011). Wanita Shalihah (calon ratu bidadari surga). Bandung: CV. Pringgandani.

Cholil, Al-Ustadz Adam. (2014). Dahsyatnya Al-Qur'an: Al-Qur'anul Karim Menjadi Petunjuk dan Solusi Bagi Umat Manusia dalam Mengarungi Samudra Kehidupan. Jakarta: AMP Press.

Eraslan, Sibel. (2012). Khadijah Ketika Rahasia Mim Tersingkap. Jakarta: Kaysa Media.

Hemdi, Yoli. (2008). Yang Terindah dari Khadijah. Jakarta: Zikrul Remaja.

Ilyas, Yunahar. Sobron, Sudarno. dan Muhaimin. 2007. Pendidikan Agama Islam. Gresik: Pusat Studi Agama dan Masyarakat Industri Universitas Muhammadiyah Gresik.

Jam'ah, Ahmad Khalil. (2007). Wanita Yang Dijamin Surga. Jakarta: Darul Falah.

Kamus isi terbuka berbasis Wiki (Kamus Versi Online/Daring). Di unduh dari: https://id.wiktionary.org/ tanggal 17 Oktober 2020.

Mardalis. (2009). Metode Penelitian suatu Pendekatan Proposal. Jakarta: Bumi Aksara.

Poerwardaminta, W.J.S. (2007). Kamus Umum Bahasa Indonesia. Jakarta: Balai Pustaka.

Siregar, Rusman. 2018. Detik-detik wafatnya istri tercinta Rasulullah. Di unduh dari: https://kalam.sindonews.com/berita/1309418/70/detik-detik-wafatnya-istri-tercintarasulullah?showpage=all tanggal 6 Desember 2020 
TAMADDUN : Jurnal Pendidikan dan Pemikiran Keagamaan

P-ISSN : 1693-3941; E-ISSN : 2722-2632

Vol. 22 No.1 Bulan Januari Tahun 2021

Toto Suryana dkk. (1997). Pendidikan Agama Islam. Bandung: Tiga Mutiara.

Wikipedia. (2020). Pengertian Wanita. Di unduh dari: https://id.wikipedia.org/wiki/Wanita tanggal 20 Oktober 2020. 